\title{
UMA MÉTRICA GRÁFICA PARA AVALIAÇÃO HOLÍSTICA DA VERDURA DE REACÇÕES LABORATORIAIS - "ESTRELA VERDE"
}

\author{
M. Gabriela T. C. Ribeiro* \\ REQUIMTE, Departamento de Química, Faculdade de Ciências, Universidade do Porto, Rua do Campo Alegre 687, Porto \\ 4169-007, Portugal
}

Dominique A. Costa e Adélio A. S. C. Machado

Departamento de Química, Faculdade de Ciências, Universidade do Porto, Rua do Campo Alegre 687, Porto 4169-007, Portugal

Recebido em 26/5/09; aceito em 9/10/09; publicado na web em 10/3/10

\begin{abstract}
A GRAFIC METRIC TO A HOLISTIC EVALUATION OF THE GREENISHNESS OF CHEMICAL REACTIONS - "GREEN STAR". A new semi-quantitative metrics, Green Star (GS), for evaluation of the global greenishness of chemical reactions used in teaching laboratories has been developed. Its aim is to help choosing the more acceptable reactions for implementing Green Chemistry (GC) and to identify suitable modifications of reaction protocols to improve the greenishness of chemistry. GS considers globally all the Twelve Principles of GC. To illustrate its construction, the tetraamminecopper(II) sulfate monohydrate laboratory synthesis, performed under several sets of conditions to pursue greenishness, is presented. A comparative study with other GC metrics showed the advantages of GS and that it accomplishes its purpose.
\end{abstract}

Keywords: green metrics; reaction greenishness improvement; green chemistry education.

\section{INTRODUÇÃO}

Num esforço de apresentar e fazer sentir aos alunos de cursos de Química o que é a Química Verde (QV) e que o seu objectivo global é a melhoria da prática da química com respeito aos seus efeitos deletérios para o ambiente e a saúde humana, tem vindo a rever-se experiências de laboratório do curso de Ensino da Química com a intenção assumida de desafiar os alunos a encontrar a QV por esforço próprio. Para isso, propõe-se-lhes experiências de síntese, que começam por realizar segundo protocolos estabelecidos (p. ex. ${ }^{1-}$ ${ }^{5}$ ), sendo depois incitados a escrutiná-los e melhorá-los, e repetir as experiências, com a meta de obter um aumento da sua verdura. ${ }^{6}$

A verdura é uma grandeza complexa e elusiva, ${ }^{6}$ constituída por variadas componentes de natureza química (por exemplo, incorporar os átomos dos reagentes no produto e não os desperdiçar em resíduos, usar reagentes e reacções seguras, etc.), ambiental (não produzir resíduos e poluentes, especialmente se tóxicos, usar matérias-primas renováveis, etc), energética, etc. Até agora, tem sido aferida por métricas reducionistas diversas, cada uma dirigida a uma componente particular, que globalmente podem ser divididas em duas categorias: métricas de massa, ${ }^{6}$ para avaliar a verdura química intrínseca das reacções em termos do cumprimento dos dois primeiros princípios da QV; e métricas ambientais, ${ }^{7,8}$ para avaliação das várias facetas de benignidade ambiental a diversas escalas, associadas aos restantes princípios. Como os parâmetros susceptíveis de avaliação são numerosos, o número de métricas propostas de ambos os tipos é elevado; e, para alguns dos parâmetros, são usadas várias métricas, não sendo transparente a escolha das mais adequadas - e, por isso, susceptível de contestação. Por outro lado, a utilização isolada de métricas de natureza reducionista, não adequadas para avaliar a verdura como um todo, tem arrastado como consequência que tenham sido adjectivadas como verdes processos, reacções, compostos, etc., que afinal, não o são (casos de "falsa QV"). ${ }^{9}$

Quando se aplicaram as métricas disponíveis na literatura no contexto educacional acima referido, sentiu-se a falta de métricas sistémicas de verdura das reacções químicas, de alcance alargado,

*e-mail: gribeiro@fc.up.pt tendo emergido a motivação para as construir. Os Doze Princípios da $\mathrm{QV},{ }^{10}$ muito utilizados para incentivar o ensino desta, são prescrições de natureza qualitativa que devem ser aplicados sistemicamente, em conjunto, na perseguição da verdura, porque mudanças nas condições de realização das reacções químicas podem implicar alterações de grau díspar em termos dos diversos princípios, melhorando a verdura no que se refere a alguns deles, mas piorando-a no que se refere a outros. Assim, surgiu a ideia de construir métricas holísticas que cobrissem todos os princípios aplicáveis em cada situação sob estudo.

Este artigo tem como primeiro objectivo descrever a concepção de uma métrica deste tipo, de natureza gráfica, que permite comparações visuais fáceis. A métrica é constituída por uma estrela de tantas pontas quantos os Princípios da QV em jogo no problema em análise, e em que o comprimento de cada ponta é tanto maior quanto melhor for o cumprimento do respectivo princípio, de modo que a área da estrela é tanto maior quanto maior for a verdura global do processo químico em estudo. Em face da sua forma, a métrica foi designada pelo nome de "Estrela Verde (EV)" (Green Star, GS).

$\mathrm{O}$ artigo inclui, como segundo objectivo, uma discussão comparativa da aplicação da EV e de métricas de massa no melhoramento da verdura, com vista a sentir as vantagens e desvantagens da EV, e a determinar que métricas de massa a devem eventualmente acompanhar para possibilitar uma mais cabal aferição da verdura. Fez-se também uma comparação com uma métrica semiquantitativa apresentada recentemente na literatura, a Ecoscale. ${ }^{11}$ A comparação foi realizada para um estudo de caso, a reacção de síntese do sulfato de tetra-aminocobre(II) monoidratado, uma experiência vulgarizada nos laboratórios de química universitários de nível introdutório, cujo protocolo foi alterado num esforço de optimização da verdura da reacção. Em Portugal esta experiência é prescrita nos programas dos anos terminais do secundário, ${ }^{12} \mathrm{e}$ foi escolhida porque se está a realizar uma avaliação sistemática da verdura das experiências destes programas.

\section{Fundamentação da "Estrela Verde" e sua construção}

Para construir a EV referente a uma experiência, começa por se inventariar todas as substâncias intervenientes: reagentes, produtos e 
coprodutos obtidos, catalizadores, solventes, agentes de purificação, secantes e resíduos formados. Para cada uma destas substâncias, recolhe-se informação acerca dos riscos para a saúde e para o ambiente, inflamabilidade e reactividade, através dos símbolos indicativos das frases de risco/segurança usados na rotulagem das embalagens dos compostos; e, ainda, informações sobre se constituem ou são obtidas de matérias-primas renováveis, bem como sobre a sua degradabilidade.

A cada substância é atribuída uma pontuação de 1 (benignidade máxima) a 3, de acordo com os riscos para a saúde humana e para o ambiente, e o risco de acidentes que podem envolver (considera-se neste caso os riscos dos acidentes para a saúde, a inflamabilidade e a reactividade), seguindo critérios que foram definidos tendo em vista o objectivo e a exequibilidade de utilização, e que são apresentados na Tabela 1(a, b). Pontuam-se também as substâncias de acordo a sua degradabilidade e se são ou não matérias-primas renováveis, seguindo os critérios apresentados na Tabela 1(c). No caso das informações recolhidas não serem consistentes para algum dos aspectos, usa-se o valor mais penalizador, por razões de segurança. A EV é construída atribuindo a pontuação 1, 2 ou 3 (máximo de verdura) a cada um dos Doze Princípios da QV, de acordo com os critérios definidos na Tabela 2 . No caso de não haver informações suficientes para pontuar algum dos princípios, atribui-se-lhe a pontuação 1 , considerando a situação mais desfavorável ou de maior risco.

Tabela 1. Critérios para a classificação das substâncias para construção das EV

\begin{tabular}{lcc}
\hline a) Riscos para a saúde humana e o ambiente das substâncias envolvidas \\
Riscos & Símbolos de risco & Pontuação \\
& $\mathrm{C}-$ corrosivo & \\
T - tóxico & 3 \\
Saúde & $\mathrm{T}+-$ muito tóxico & \\
& $\mathrm{Xn}-$ prejudicial \\
& $\mathrm{X}$ - irritante & 2 \\
& Nenhuma indicação & 1 \\
Ambiente & $\mathrm{N}-$ perigoso para o ambiente & 3 \\
& Nenhuma indicação & 1 \\
\hline
\end{tabular}

b) Riscos de acidente das substâncias envolvidas

\begin{tabular}{|c|c|c|}
\hline \multirow[t]{3}{*}{ Riscos } & Símbolos de risco & Pontuação \\
\hline & $\mathrm{C}$ - corrosivo & \\
\hline & $\mathrm{T}$ - tóxico & 3 \\
\hline \multirow[t]{3}{*}{ Saúde } & $\mathrm{T}+-$ muito tóxico & \\
\hline & $\begin{array}{c}\mathrm{Xi} \text { - irritante } \\
\mathrm{Xn}-\text { prejudicial }\end{array}$ & 2 \\
\hline & Nenhuma indicação & 1 \\
\hline \multirow[t]{2}{*}{ Inflamabilidade } & $\begin{array}{c}\mathrm{F}-\text { muito inflamável } \\
\mathrm{F}+- \text { extremanente inflamável }\end{array}$ & 3 \\
\hline & Nenhuma indicação & 1 \\
\hline \multirow[t]{3}{*}{ Reactividade } & E-explosivo & 3 \\
\hline & $\mathrm{O}$ - agente oxidante & 3 \\
\hline & Nenhuma indicação & 1 \\
\hline
\end{tabular}

c) Degradabilidade e renovabilidade das substâncias envolvidas

Características

Critérios

Pontuação

Não degradáveis ou que não possam ser tratados para se obter a sua degradação em produtos de degradação inócuos

Degradabilidade

Possam ser tratadas para obter degradação com produtos de degradação inócuos

Degradáveis com produtos de degradação inócuos

Renovabilidade

$$
\text { Não renováveis }
$$$$
\text { Renováveis }
$$

Para o máximo de verdura, a pontuação será 3 para todos os princípios e obtém-se uma estrela de área (verdura) máxima, conforme se apresenta na Figura 1a. O mínimo de verdura corresponderá à pontuação de 1 para todos os princípios, sendo este caso de verdura nula (área mínima) representado na Figura 1b. Nestas figuras, a EV é representada apenas com dez dimensões, cada uma referente a um princípio da QV - os princípios 4 e 11 foram excluídos, já que no ensino não se costuma realizar a concepção de novos produtos químicos, à qual estes princípios se aplicam.
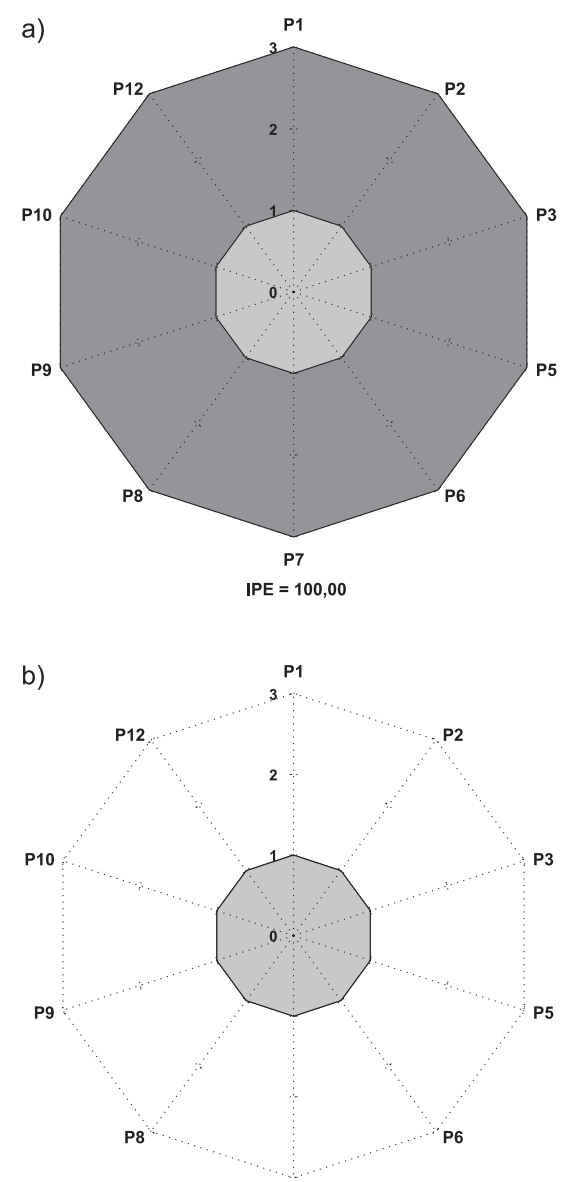

Figura 1. $a$-Estrela de verdura máxima; $b$ - estrela de verdura nula

Em certos casos, pode ser difícil a mera comparação visual das estrelas para avaliar o aumento de verdura. Por essa razão calculou-se também a percentagem de área verde da estrela relativamente à área de uma estrela de verdura máxima, (100 x área verde da estrela/área verde da estrela de verdura máxima) - a que se chamou Índice de Preenchimento da Estrela (IPE). Para a estrela de verdura máxima, IPE=100, para a de mínima, IPE=0.

\section{MÉTRICAS DE MASSA DA QV}

Com base nos dados obtidos para as experiências de síntese do sulfato de tetra-aminocobre(II) monoidratado realizadas com grande excesso de amoníaco e em condições próximas das estequiométricas, além da EV, foram calculados o rendimento e as seguintes métricas de massa da QV: ${ }^{6}$

\section{Métricas de minimização da produção de resíduos}

Factor E, definido como a razão de massas entre a totalidade da massa dos resíduos produzidos e a massa de produto obtido; intensidade de massa (MI), definida como a razão entre a massa total de materiais usados num processo (reagentes, solventes, outros materiais auxiliares, etc.) e a massa de produto obtido. 
Tabela 2. Componentes e pontuações para construção das EV ( $\mathrm{p}$ = pontuação)

\begin{tabular}{|c|c|c|}
\hline Princípio da QV & Critérios & $\mathrm{p}$ \\
\hline \multirow[t]{3}{*}{ P1 - Prevenção } & Todos os resíduos são inócuos ( $\mathrm{p}=1$, tabela 1a) & 3 \\
\hline & $\begin{array}{l}\text { Resíduos que envolvam um risco moderado para a saúde e ambiente ( } \mathrm{p}=2 \text {, tabela 1a, pelo menos para uma substân- } \\
\text { cia, sem substâncias com } \mathrm{p}=3 \text { ) }\end{array}$ & 2 \\
\hline & Formação de pelo menos um resíduo que envolva um risco elevado para a saúde e ambiente ( $\mathrm{p}=3$, tabela 1a) & 1 \\
\hline \multirow[t]{4}{*}{ P2- Economia atómica } & Reacções sem reagentes em excesso $(<10 \%)$ e sem formação de coprodutos & 3 \\
\hline & Reacções sem reagentes em excesso $(<10 \%)$ e com formação de coprodutos & 2 \\
\hline & Reacções com reagentes em excesso (>10\%) e sem formação de coprodutos & 2 \\
\hline & Reacções com reagentes em excesso (>10\%) e com formação de coprodutos & 1 \\
\hline \multirow[t]{3}{*}{ P3 - Sínteses menos perigosas } & Todas as substâncias envolvidas são inócuas ( $\mathrm{p}=1$, tabela 1a) & 3 \\
\hline & $\begin{array}{l}\text { As substâncias envolvidas apresentam um risco moderado para a saúde e ambiente ( } \mathrm{p}=2 \text {, tabela } 1 \mathrm{a} \text {, pelo menos para } \\
\text { uma substância, sem substâncias com } \mathrm{p}=3 \text { ) }\end{array}$ & 2 \\
\hline & Pelo menos uma das substâncias envolvidas apresenta um risco elevado para a saúde e ambiente ( $\mathrm{p}=3$, tabela 1a) & 1 \\
\hline \multirow{3}{*}{$\begin{array}{l}\text { P5 - Solventes e outras } \\
\text { substâncias auxiliares mais } \\
\text { seguras }\end{array}$} & Os solventes e as substâncias auxiliares não existem ou são inócuas ( $\mathrm{p}=1$, tabela 1a) & 3 \\
\hline & $\begin{array}{l}\text { Os solventes e as substâncias auxiliares usadas envolvem um risco moderado para a saúde e ambiente ( } \mathrm{p}=2 \text {, tabela } \\
\text { 1a, pelo menos para uma substância, sem substâncias com } \mathrm{p}=3 \text { ) }\end{array}$ & 2 \\
\hline & $\begin{array}{l}\text { Pelo menos um dos solventes ou uma das substâncias auxiliares usadas envolve um risco elevado para a saúde e } \\
\text { ambiente }(\mathrm{p}=3 \text {, tabela 1a) }\end{array}$ & 1 \\
\hline \multirow{3}{*}{$\begin{array}{l}\text { P6 - Planificação para } \\
\text { conseguir eficácia energética }\end{array}$} & Temperatura e pressão ambientais & 3 \\
\hline & Pressão ambiental e temperatura entre $0^{\circ} \mathrm{C}$ e $100^{\circ} \mathrm{C}$ que implique arrefecimento ou aquecimento & 2 \\
\hline & Pressão diferente da ambiental e/ou temperatura muito afastada da ambiental & 1 \\
\hline \multirow{3}{*}{$\begin{array}{l}\text { P7 - Uso de matérias primas } \\
\text { renováveis }\end{array}$} & Todos os reagentes/matérias-primas/recursos envolvidos são renováveis ( $\mathrm{p}=1$, tabela 1c) & 3 \\
\hline & $\begin{array}{l}\text { Pelo menos um dos reagentes/matérias-primas/recursos envolvidos é renovável, não se considera a água ( } \mathrm{p}=1 \text {, tabela } \\
\text { 1c) }\end{array}$ & 2 \\
\hline & Nenhum dos reagentes/matérias-primas/recursos envolvidos é renovável, não se considera a água ( $\mathrm{p}=3$, tabela 1c) & 1 \\
\hline \multirow{3}{*}{$\begin{array}{l}\text { P8 - Redução de } \\
\text { derivatizações }\end{array}$} & Não se usam derivatizações & 3 \\
\hline & Usa-se apenas uma derivatização ou operação semelhante & 2 \\
\hline & Usam-se várias derivatizações ou operações semelhantes & 1 \\
\hline \multirow[t]{3}{*}{ P9 - Catalisadores } & Não se usam catalisadores ou os catalisadores são inócuos ( $\mathrm{p}=1$, tabela 1a) & 3 \\
\hline & Utilizam-se catalisadores que envolvem um risco moderado para a saúde e ambiente ( $\mathrm{p}=2$, tabela 1a) & 2 \\
\hline & Utilizam catalisadores que envolvem um risco elevado para a saúde e ambiente ( $\mathrm{p}=3$, tabela $1 \mathrm{a})$ & 1 \\
\hline \multirow{3}{*}{$\begin{array}{l}\text { P10 - Planificação para a } \\
\text { degradação }\end{array}$} & Todas as substâncias envolvidas são degradáveis com os produtos de degradação inócuos ( $\mathrm{p}=1$, tabela 1c) & 3 \\
\hline & $\begin{array}{l}\text { Todas as substâncias envolvidas que não são degradáveis podem ser tratados para obter a sua degradação com os } \\
\text { produtos de degradação inócuos ( } \mathrm{p}=2 \text {, tabela } 1 \mathrm{c} \text { ) }\end{array}$ & 2 \\
\hline & $\begin{array}{l}\text { Pelo menos uma das substâncias envolvidas não é degradável nem pode ser tratada para obter a sua degradação com } \\
\text { produtos de degradação inócuos ( } \mathrm{p}=3 \text {, tabela 1c) }\end{array}$ & 1 \\
\hline \multirow{3}{*}{$\begin{array}{l}\text { P12 - Química inerentemente } \\
\text { mais segura quanto à } \\
\text { prevenção de acidentes }\end{array}$} & As substâncias envolvidas apresentam um baixo risco de acidente químico ( $\mathrm{p}=1$, tabela $1 \mathrm{~b})$ & 3 \\
\hline & $\begin{array}{l}\text { As substâncias envolvidas apresentam um risco moderado de acidente químico(p=2, tabela } 1 b \text {, pelo menos para uma } \\
\text { substância, sem substâncias com } p=3 \text { ) }\end{array}$ & 2 \\
\hline & As substâncias envolvidas apresentam um risco elevado de acidente químico ( $\mathrm{p}=3$, tabela $1 \mathrm{~b}$ ) & 1 \\
\hline
\end{tabular}

\section{Métricas de incorporação dos átomos dos reagentes no produto}

Utilização atómica percentual (AU), definida como a razão entre a massa do produto obtido e a soma das massas de todas as substâncias produzidas na reacção (produto e coprodutos), expressa em percentagem. Neste caso, considerou-se a massa de resíduos em vez da massa de coprodutos, já que esta era impossível de obter experimentalmente. A massa de resíduos foi calculada como a diferença entre a massa de reagentes estequiométricos e a massa de produto obtido (só se o rendimento fosse $100 \%$ a massa de coprodutos seria igual à massa de resíduos).

Economia atómica percentual (AE), definida como a razão entre a massa de átomos de reagentes que são incorporados no produto desejado e a massa total de átomos nos reagentes, expressa em percentagem (o termo reagentes refere-se apenas aos reagentes estequiométricos).

Eficiência de massa (RME), definida como a razão entre a massa do produto efectivamente obtido e a massa total de reagentes estequiométricos usados na reacção, expressa em percentagem.

Eficiência elementar percentual de cobre (CuEE), definida como a razão entre a massa do elemento no produto obtido e a massa do elemento nos reagentes estequiométricos, expressa em percentagem.

As métricas RME e EE são usadas em processos industriais ${ }^{13}$ e, pela facilidade de cálculo, mostraram-se mais úteis para avaliar a incorporação dos átomos de reagentes no produto.

\section{REALIZAÇÃO EXPERIMENTAL}

Foram realizadas, em laboratório, um conjunto de experiências da síntese do sulfato de tetra-aminocobre(II) monoidratado com os reagentes sulfato de cobre pentaidratado e amoníaco, seguindo um protocolo publicado. ${ }^{14}$ Neste protocolo, referente a macroescala, era usado um grande excesso de amoníaco. Para aumentar a verdura optimizou-se a experiência procurando condições próximas das estequiométricas (a aproximação à estequiometria permite reduzir os resíduos e melhorar a economia atómica). As experiências foram também realizadas a microescala (diminuir a escala reduz quer a quantidade de resíduos produzidos, logo também o custo de tratamento e/ou deposição dos mesmos, quer a quantidade de reagentes utilizados, logo o seu cus- 
to $\left.^{15,16}\right)$, para avaliar a sensibilidade das métricas às mudanças de escala.

A partir dos dados sobre as experiências, além da EV, foram também calculadas métricas quantitativas de massa (rendimento e métricas da QV descritas acima) e a EcoScale. ${ }^{11}$ Os resultados foram comparados de forma a identificar e avaliar a sensibilidade das várias métricas a aumentos de verdura obtidos com a realização das experiências em condições próximas das estequiométricas. Foi também avaliado se a realização das experiências a microescala tinha influência nos valores das métricas calculadas.

\section{Sínteses a macroescala}

Dissolveram-se cerca de 2,0 g (8,0 mM) de sulfato de cobre pentaidratado em $10 \mathrm{~mL}$ de água desionizada, num copo Béquer de $50 \mathrm{~mL}$. Em seguida juntaram-se $10 \mathrm{~mL}$ de solução de amoníaco a $25 \%$ (132,1 mM), agitando-se até que o precipitado inicial azul claro de hidróxido de cobre(II) se dissolvesse para formar uma solução de cor azul forte. Juntou-se então $10 \mathrm{~mL}$ de etanol e deixou-se arrefecer em banho de gelo durante $1 \mathrm{~h}$, até precipitação de um sólido azul forte, de sulfato de tetra-aminocobre(II) monoidratado. Após a cristalização, filtraram-se os cristais, por sucção, que foram lavados com $5 \mathrm{~mL}$ de etanol, deixando-a secar no filtro durante cerca de 10 min. Os cristais foram deixados num dessecador durante 1 semana e pesados, obtendo-se cerca de 1,8 g (7,3 mM). Neste protocolo, ${ }^{14}$ é usado um grande excesso de amoníaco (cerca de 300\%). Realizaramse 4 experiências e foi obtido um rendimento de cerca de $93 \%$ (média $92,8 \%$, desvio padrão $\pm 1,6$ ) (literatura: $90 \%$ ).

Com base neste protocolo, procurou optimizar-se a experiência no sentido de conseguir condições próximas das estequiométricas, sem prejuízo do rendimento. Para isso, foi necessário fazer várias experiências para encontrar um volume da solução de amoníaco que fosse suficiente para garantir que o precipitado inicial azul claro de hidróxido de cobre(II) se dissolvia e que se obtinham valores elevados para o rendimento. Após ter sido obtida a proporção óptima, fizeram-se experiências seguindo o protocolo anterior mas com a proporção optimizada, apenas $7 \%$ de excesso de amoníaco $(34,4 \mathrm{mM})$, tendo-se obtido um rendimento de cerca de $95 \%$ ( 3 experiências, média 95,4\%, desvio padrão $\pm 1,7$ ).

\section{Sínteses a microescala}

As experiências a microescala foram realizadas a uma escala de $1 / 20$. As experiências em condições não estequiométricas foram realizadas reduzindo proporcionalmente as quantidades de todos os reagentes, tendo sido obtido um rendimento de cerca de $92 \%$ (3 experiências, média $91,6 \%$, desvio padrão $\pm 2,3$ ).

Para optimizar a experiência quanto a condições próximas das estequiométricas e rendimento, foi seguido o mesmo processo que para as experiências a macroescala. Para $7 \%$ de excesso de amoníaco (1,7 mM), o rendimento obtido foi de cerca de $92 \%$ (3 experiências, média $91,9 \%$, desvio padrão $\pm 0,6$ ).

\section{Estrela Verde}

A partir dos dados coligidos do modo indicado atrás, construíram-se duas tabelas (Tabelas $1 \mathrm{~S}$ e $2 \mathrm{~S}$, material suplementar), onde se indicam as componentes e pontuações para construir as estrelas verdes. As EV são apresentadas na Figura 2a, para condições de grande excesso de amoníaco e na Figura 2b, para condições quase estequiométricas.

Pela mera comparação visual das EV pode verificar-se que, para condições próximas das estequiométricas (Figura 2b), a área aumenta, por melhoria das pontuações no primeiro princípio (reduzem-se os resíduos no que se refere a substâncias perigosas, pois admite-se que
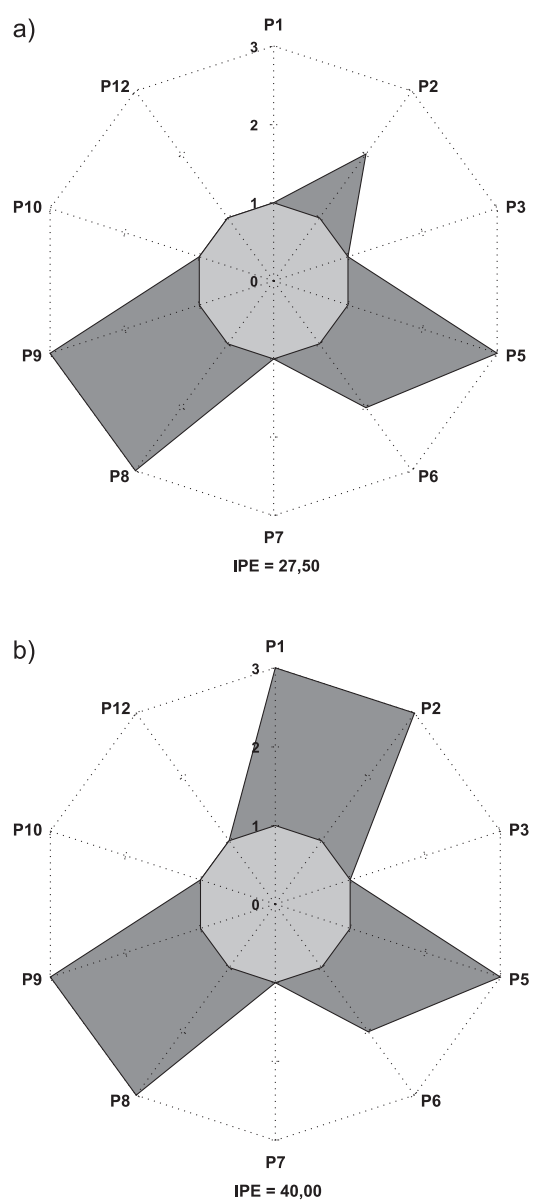

Figura 2. a-EV para a sintese do sulfato de tetra-aminocobre(II) monoidratado (grande excesso de amoníaco); $b-E V$ para a síntese do sulfato de tetra-aminocobre(II) monoidratado (proporção quase estequiométrica)

não será de considerar o excesso de substâncias estequiométricas nos resíduos) e no segundo princípio (melhora a economia atómica). Os valores de IPE, incluídos nas figuras, confirmam a análise visual - o índice sobe de 27,5 para 40,0 (se se considerar o coproduto água, sobe de 25,0 para 35,0).

Não obstante esse aumento, a área verde (IPE=40 para a Figura 2b) está longe do máximo. Este facto sugere que seria preferível preterir esta experiência em favor de outra experiência de síntese, em condições estequiométricas, que satisfizesse os mesmos objectivos pedagógicos, mas que usasse substâncias com menor grau de toxicidade.

\section{RESULTADOS E DISCUSSÃO}

\section{Considerações sobre a comparação entre a EV e as métricas de massa da QV}

A EV envolve a consideração de aspectos relacionados com: os riscos para a saúde e ambiente de todas as substâncias envolvidas ( $3^{\circ}$ princípio), a eficiência energética ( $6^{\circ}$ princípio), a utilização de matérias-primas renováveis ( $7^{\circ}$ princípio), a degradabilidade das substâncias envolvidas ( $10^{\circ}$ princípio) e os riscos de acidente químico das substâncias envolvidas ( $12^{\circ}$ princípio). Todos estes aspectos são considerados na pontuação da EV, mas não têm qualquer reflexo no valor das métricas de massa da QV.

No que se refere à existência de derivatizações ( $8^{\circ}$ princípio), a redução do seu número aumentará a verdura e a pontuação da $\mathrm{EV}$ aumentará também relativamente a esse princípio. Como esta redução 
implica normalmente uma diminuição da quantidade de resíduos, os valores das métricas de massa da QV indicarão também um aumento de verdura e haverá concordância entre a EV e estas métricas.

Relativamente à utilização de solventes e outras substâncias auxiliares ( $5^{\circ}$ princípio), desde que inócuos, não haverá qualquer penalização na EV enquanto que os valores das métricas de massa da QV indicarão diminuição da verdura. No caso desses solventes e outras substâncias auxiliares apresentarem riscos para a saúde humana e/ou para o ambiente, a EV já indicará uma diminuição da verdura.

A utilização de catalizadores ( $9^{\circ}$ princípio) normalmente implica a diminuição da quantidade de resíduos e os valores das métricas de massa da QV indicarão um aumento de verdura, mas se os catalizadores apresentarem riscos para a saúde humana e para o ambiente a EV indicará uma diminuição da verdura.

Pelas razões expostas nem sempre haverá concordância da EV com as métricas de massa da QV no caso da utilização de solventes e outras substâncias auxiliares e de catalizadores, mas a EV, em consequência da sua natureza holística, mostra-se sensível a mais componentes da verdura.

\section{Comparação das EV com as métricas de massa da QV}

Na Tabela 3 apresentam-se os valores obtidos, nos quatro tipos de experiências realizadas, para o rendimento e as métricas de massa da QV (os solventes não foram considerados nos cálculos). Para cada uma das sínteses, obteve-se sempre o mesmo valor para as métricas AU e RME, já que o valor de AU foi calculado com base na massa de resíduos e não na massa de coprodutos. Foi também calculado o valor teórico de $\mathrm{AE}$ (considerou-se que não havia perdas no processo e que todos os reagentes estequiométricos foram transformados em produto e coprodutos), tendo sido obtido um valor de 77,3. Este valor será de $100 \%$ se a água for ignorada como coproduto.

Quando se reduziu o excesso de reagente, quer nas experiências a macroescala quer a microescala, o factor E diminuiu cerca de $70 \%$ e a MI cerca de $40 \%$, mostrando que se reduziu a perda de átomos em resíduos. A massa de resíduos diminuiu, bem como a massa de reagentes, já que o excesso de amoníaco baixou de cerca de 300 para cerca de $7 \%$, mas o rendimento não foi prejudicado pela realização da síntese em proporções mais próximas das estequiométricas.

A EV, no que se refere aos resíduos formados, considera a natureza dos resíduos e não a sua massa. Como em condições próximas da estequiometria praticamente não ocorre a presença de reagentes estequiométricos nos resíduos, eliminou-se nestes todas as substâncias que apresentavam um elevado risco para a saúde humana e para o ambiente. Assim, relativamente ao $1^{\circ}$ princípio (princípio da prevenção), a pontuação da EV passou de 1 para 3. Neste caso houve concordância entre a EV e as métricas de massa consideradas relativamente ao aumento de verdura. Em casos em que haja formação de uma pequena quantidade de resíduos, mas de grande toxicidade, o factor E e MI serão baixos, sugerindo verdura razoável, mas a EV apresentará uma pontuação mínima para o $1^{\circ}$ princípio, pois a EV não considera a quantidade de resíduos e no factor E e MI não é avaliada a natureza dos resíduos. Em situações deste tipo, a EV é sensível a deterioração da verdura, em contraste com o que sucede com estas duas métricas de massa.

Concomitantemente, os valores de AU e RME aumentaram cerca de $70 \%$, mostrando que cresceu a incorporação dos átomos dos reagentes no produto desejado. A massa de produto manteve-se praticamente inalterada e a massa de reagentes estequiométricos diminuiu com a aproximação à estequiometria. Assim, o aumento de "verdura atómica de massa" ("uso produtivo dos átomos") foi comprovado através dos valores das métricas de massa. Este facto é sentido pela $\mathrm{EV}$, que considera a incorporação dos átomos dos reagentes na pontuação do segundo princípio (princípio da economia atómica). Neste caso, quando as condições se aproximaram da estequiometria, a pontuação da EV passou de 2 (não há formação de coprodutos, a não ser água) para 3 .

As métricas de massa da QV indicam apenas a necessidade de reduzir resíduos e incorporar mais átomos dos reagentes no produto (aumentar a "produtividade atómica"). A EV é uma métrica holística que procura cobrir todos os princípios da QV aplicáveis à situação em estudo. Neste caso, atendendo a que o aumento de verdura resultou apenas da aproximação à estequiometria, esta foi reflectida nos primeiro e segundo princípios, mas a pontuação dos outros princípios não teve qualquer influência na $\mathrm{EV}$

\section{Comparação das EV com a EcoScale}

Para comparação foi também utilizada a métrica EcoScale, ${ }^{11}$ a única métrica conhecida com objectivo semelhante, cujo valor obtido foi de 76,4 para as experiências a macroescala com grande excesso de amoníaco e de 77,7 para proporções próximas das estequiométricas. Segundo os autores desta métrica, estes dois valores correspondem a uma classificação "excelente", pelo que a EcoScale indica que as experiências em diferentes proporções são ambas do mesmo nível em termos de verdura. A comparação das EV mostra que esta conclusão não é válida, já que é claro o aumento da verdura (estrela mais cheia) para proporções mais próximas das estequiométricas.

A EcoScale apresenta algumas limitações relativamente à EV, pois não tem em consideração os seguintes aspectos sentidos por esta: a segurança dos resíduos produzidos, a economia atómica, a utilização de substâncias renováveis e a degradabilidade das substâncias envolvidas. Estas limitações explicam a quase insensibilidade á mudança de condições referida acima. Por outro lado, ao contrário da EV, o cálculo da EcoScale exige o valor do rendimento obtido; como os protocolos apresentados na literatura nem sempre referem

Tabela 3. Métricas de massa para a síntese do sulfato de tetra-aminocobre(II) monoidratado*

\begin{tabular}{|c|c|c|c|c|c|c|c|c|c|c|}
\hline \multirow{3}{*}{ Métricas de massa } & \multicolumn{5}{|c|}{ Macroescala } & \multicolumn{5}{|c|}{ Microescala } \\
\hline & \multicolumn{2}{|c|}{$\begin{array}{l}\text { Grande excesso } \\
\qquad N=4\end{array}$} & \multicolumn{2}{|c|}{$\begin{array}{l}\text { Quase estequiométrica } \\
\qquad \mathrm{N}=3\end{array}$} & \multirow{2}{*}{$\begin{array}{c}\text { Variação** } \\
\%\end{array}$} & \multicolumn{2}{|c|}{ Grande excesso $\mathrm{N}=3$} & \multicolumn{2}{|c|}{$\begin{array}{l}\text { Quase estequiométrica } \\
\qquad \mathrm{N}=3\end{array}$} & \multirow{2}{*}{$\begin{array}{c}\text { Variação** } \\
\%\end{array}$} \\
\hline & Média & $\begin{array}{l}\text { Desvio } \\
\text { padrão }\end{array}$ & Média & $\begin{array}{l}\text { Desvio } \\
\text { padrão }\end{array}$ & & Média & $\begin{array}{l}\text { Desvio } \\
\text { padrão }\end{array}$ & Média & $\begin{array}{l}\text { Desvio } \\
\text { padrão }\end{array}$ & \\
\hline Rendimento $\%$ & 92,8 & 1,6 & 95,4 & 1,7 & 2,8 & 91,6 & 2,3 & 91,9 & 0,6 & 0,3 \\
\hline Factor E & 1,33 & 0,04 & 0,38 & 0,02 & $-71,4$ & 1,4 & 0,1 & 0,43 & 0,01 & $-69,3$ \\
\hline MI & 2,33 & 0,04 & 1,38 & 0,02 & $-40,8$ & 2,4 & 0,1 & 1,43 & 0,01 & $-40,4$ \\
\hline $\mathrm{RME}=\mathrm{AU}$ & 43,0 & 0,7 & 72,7 & 1,3 & $+69,1$ & 42,4 & 0,9 & 70,0 & 0,4 & $+65,1$ \\
\hline $\mathrm{CuEE}$ & 92,8 & 1,6 & 95,4 & 1,7 & 2,8 & 91,6 & 2,3 & 91,9 & 0,6 & 0,3 \\
\hline
\end{tabular}

* N - Número de experiências. MI - Intensidade de massa. RME - Eficiência de massa percentual. AU - Utilização atómica percentual. CuEE - Eficiência elementar percentual do cobre. **Variação \%=(coluna "média quase estequiométrica"- coluna "média grande excesso") x 100/coluna "média grande excesso" 
o rendimento típico, aquela métrica não pode ser usada na avaliação prévia da verdura de uma reacção química sem ser necessário realizar a experiência.

Pelas razões expostas, a EV parece ser mais útil do que a $E c o S$ cale na avaliação da verdura de reacções químicas, nomeadamente em laboratórios de ensino.

\section{Comparação das verduras a macro e microescala}

Os resultados indicaram que não há variação nos valores das métricas EV e EcoScale quando se varia a escala de realização da síntese do presente composto quanto à quantidade de reagentes usados. Por outro lado, também os valores das métricas de massa revelaram que a realização das experiências a microescala não provocou qualquer aumento de verdura atómica relativamente à macroescala (Tabela 3). Este facto resulta de as métricas de massa da QV terem como base de cálculo a massa de produto obtido e de os rendimentos serem semelhantes a macro e microescala.

A utilização da microescala é aconselhada nos laboratórios de ensino com base numa perspectiva de prevenção da poluição, uma vez que reduz significativamente a quantidade de reagentes usados e de resíduos produzidos; além disso, há redução dos custos experimentais, redução do tempo de exposição aos materiais potencialmente tóxicos e menores tempos de reacção. ${ }^{15,16}$ Por outro lado, a microescala permite a utilização de uma maior variedade de substâncias químicas já que, sendo a escala diminuída, podem usar-se materiais dispendiosos ou reagentes/produtos mais problemáticos quanto a efeitos nocivos, que não seriam seguros em macroescala. Estes aspectos não são captados pelas métricas da $\mathrm{QV}$, porque as vantagens da microescala são exercidas no âmbito do "paradigma do risco" (diminuição da exposição resultante da diminuição de quantidades), ao passo que a QV é desenvolvida no "paradigma ecológico" - diminui proactivamente o risco por diminuição da perigosidade ( risco = perigosidade $\mathrm{x}$ exposição).

\section{CONCLUSÕES}

Embora estes resultados precisem de ser aprofundados com mais experiências sobre outras reacções de síntese que envolvam outros factores que afectem a verdura, presentemente em curso, a EV apresenta-se como uma métrica útil na avaliação da verdura de reacções químicas, atendendo a que: a EV é sensível a variações da verdura atómica da reacção, nomeadamente quando se realizam as experiências em diferentes proporções estequiométricas; pode ser usada na avaliação prévia da verdura de uma reacção química a partir de um protocolo, sem ser necessário realizar a experiência; permite uma comparação semiquantitativa da verdura por mera análise visual, sem prejuízo da utilização do valor numérico do IPE, expresso numa escala de 0 a 100; permite detectar, por simples inspecção visual, quais os aspectos a optimizar para conseguir uma maior verdura; é de construção simples, embora nem sempre seja possível obter todas as informações requeridas, nomeadamente no que se refere à degradabilidade das substâncias; é sensível aos diversos aspectos que devem ser considerados quando se discute a verdura de uma reacção, pois atende aos 12 princípios da QV de uma forma global e sistemática.

No caso da síntese considerada, o protocolo de literatura sugeria o uso de um grande excesso de um reagente, mas a sua optimização demonstrou que tal excesso não era necessário - o mesmo rendimento podia ser atingido só com um ligeiro excesso. Este resultado exemplifica uma das vias pelas quais a química tradicional pode evoluir para a QV - mediante revisões de procedimentos que proporcionem incrementos graduais de verdura. A EV mostrou ser capaz de avaliar as pequenas diferenças de verdura alcançada com modificações deste tipo - e evidenciar aos alunos que a perseguição da verdura pode ser feita mediante pequenos aumentos procurados com perseverança.

A inclusão da QV no ensino pode ajudar a desenvolver nos alunos um novo olhar mais optimista sobre a possibilidade de fazer evoluir a Química no sentido do desenvolvimento sustentável, sem comprometer a integridade do conhecimento químico. Para se fazer sentir a QV aos alunos, a realização de experiências em paralelo, ou em sequência, com o objectivo de procurar a optimização da verdura é um bom método, e a EV parece ser uma métrica adequada para utilizar com este fim.

\section{MATERIAL SUPLEMENTAR}

Está disponível em http://quimicanova.sbq.org.br, na forma de arquivo PDF, com acesso livre. Inclui Tabelas $1 \mathrm{~S}$ e $2 \mathrm{~S}$, que apresentam as componentes e as pontuações necessárias à construção das EV e as versões a cores das Figuras que apresentam as EV (1S e 2S).

\section{AGRADECIMENTOS}

À colaboração na realização das sínteses dos alunos estagiários para professores do Ensino Secundário, A. E. R. Neves e B. M. A. Faria.

\section{REFERÊNCIAS}

1. Szafran, Z.; Pike, R. M.; Sigh, M. M.; Microscale Inorganic Chemistry, Wiley: New York, 1991.

2. Williamson, K. L.; Minard, R. D.; Masters, K. M.; Macroscale and Microscale Organic Experiments, $5^{\text {th }}$ ed., Houghton Mifflin Company: Boston, 2007.

3. Pavia, D. L.; Lampman, G. M.; Kriz, G. S.; Engel, R. G.; Organic Laboratory Techniques, $2^{\text {nd }}$ ed., Harcourt Brace College Publisher: Orlando, 1995.

4. Pass, G.; Sutcliffe, H.; Practical Inorganic Chemistry, $2^{\text {nd }}$ ed., Chapman and Hall: New York, 1974.

5. Adams, D. M.; Raynor, J. B.; Advanced Practical Inorganic Chemistry, Wiley: London, 1965.

6. Machado, A. A. S. C.; Química - Bol. S. P. Q. 2007, 107, 47.

7. Frosch, R. A.; Industrial Environmental Performance Metrics - Challenges and Opportunities, National Academy Press: Washington, 1999.

8. Allen, D. T.; Shonnard, D. R.; Green Engineering - Environmentally Conscious Design of Chemical Processes, Prentice-Hall: Upper Saddle River, 2002.

9. Machado, A. A. S. C.; Química - Bol. S. P. Q. 2008, 110, 33.

10. Anastas, P. T.; Warner, J. C.; Green Chemistry - Theory and Practice, Oxford Press: Oxford, 1998.

11. van Aken, K.; Strekowski, L.; Patiny, L.; Beilstein J. Org. Chem. 2006, 2,1 .

12. http://sitio.dgidc.min-edu.pt/secundario/paginas/programas_es_f.aspx, acessada em Outubro 2009.

13. Curzons, A. D.; Constable, D. J. C.; Mortimer, D. N.; Cunningham, V. L.; Green Chemistry 2001, 3, 1.

14. Clareen, S. S.; Marshall, S. R.; Price, K. E.; Royall, M. B.; Yoder, C. H.; Schaeffer, R. W.; J. Chem. Educ. 2000, 77, 904.

15. Singh, M. M; Szafran, Z; Pike, R. M.; J. Chem. Educ 1999, 76, 1684.

16. Szafran, Z.; Singh, M. M; Pike, R. M.; Educación Química 2000, 172. 


\section{UMA MÉTRICA GRÁFICA PARA AVALIAÇÃO HOLÍSTICA DA VERDURA DE REACÇÕES LABORATORIAIS -} "ESTRELA VERDE"

\section{Gabriela T. C. Ribeiro*}

REQUIMTE, Departamento de Química, Faculdade de Ciências, Universidade do Porto, Rua do Campo Alegre 687, Porto 4169-007, Portugal

Dominique A. Costa e Adélio A. S. C. Machado

Departamento de Química, Faculdade de Ciências, Universidade do Porto, Rua do Campo Alegre 687, Porto 4169-007, Portugal
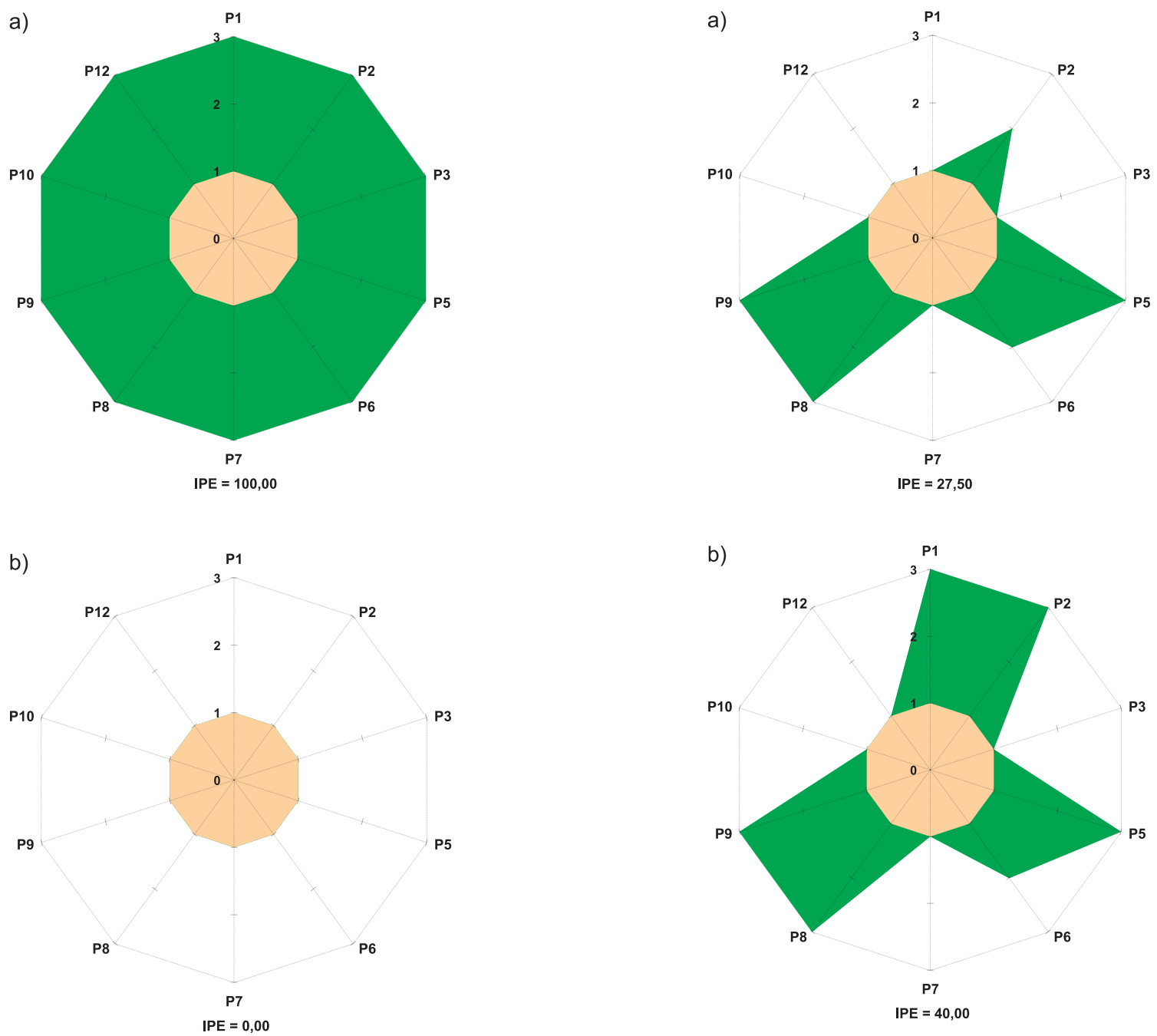

Figura 1S. a - Estrela de verdura máxima; $b$ - estrela de verdura nula

Figura 2S. a - EV para a síntese do sulfato de tetra-aminocobre(II) monoidratado (grande excesso de amoníaco); $b$ - EV para a síntese do sulfato de tetra-aminocobre(II) monoidratado (proporção quase estequiométrica)

*e-mail: gribeiro@fc.up.pt 
Tabela 1S. Riscos envolvidos na síntese do sulfato de tetra-aminocobre(II) monoidratado

\begin{tabular}{|c|c|c|c|c|}
\hline Reagentes & Símbolos & $\begin{array}{c}\text { Pontuação de riscos } \\
\text { para a saúde }\end{array}$ & $\begin{array}{c}\text { Pontuação de riscos } \\
\text { para o ambiente }\end{array}$ & $\begin{array}{c}\text { Pontuação de riscos } \\
\text { de acidente }\end{array}$ \\
\hline \multicolumn{5}{|l|}{ Reagentes estequionétricos } \\
\hline Solução de amoníaco & $\mathrm{C}, \mathrm{N}$ & 3 & 3 & 3 \\
\hline Sulfato de cobre pentaidratado & $\mathrm{Xn}, \mathrm{N}$ & 2 & 3 & 2 \\
\hline \multicolumn{5}{|l|}{ Solventes } \\
\hline Água & - & 1 & 1 & 1 \\
\hline Etanol & $\mathrm{F}$ & 1 & 1 & 3 \\
\hline \multicolumn{5}{|l|}{ Produto } \\
\hline Sulfato de tetraaminocobre(II) monoidratado & $\mathrm{Xi}$ & 2 & 1 & 2 \\
\hline \multicolumn{5}{|l|}{ Resíduos } \\
\hline Etanol & $\mathrm{F}$ & 1 & 1 & 3 \\
\hline Amoníaco (aq) & $\mathrm{C}, \mathrm{N}$ & 3 & 3 & 3 \\
\hline
\end{tabular}

Tabela 2S. Componentes e pontuações para construir a Estrela Verde com base nos símbolos de risco

\begin{tabular}{|c|c|c|c|c|}
\hline PRINCÍPIOS & $\begin{array}{l}\text { Pontuação } \\
\text { grande excesso } \\
\text { de amoníaco } \\
\end{array}$ & Justificação & $\begin{array}{c}\text { Pontuação } \\
\text { quase } \\
\text { estequiométrica } \\
\end{array}$ & Justificação \\
\hline P1 - Prevenção & 1 & Amoníaco $(\mathrm{N})$ nos resíduos & 3 & $\begin{array}{l}\text { Não se considera amoníaco }(\mathrm{N}) \text { nos resí- } \\
\text { duos, condições quase estequiométricas }\end{array}$ \\
\hline P2- Economia atómica & 2 & Grande excesso de amoníaco e sem coprodutos & 3 & $\begin{array}{c}\text { Excesso de amoníaco }<10 \% \text { e sem } \\
\text { coprodutos }\end{array}$ \\
\hline $\begin{array}{l}\text { P3 - Sínteses menos } \\
\text { perigosas }\end{array}$ & 1 & Sulfato de cobre $(\mathrm{N})$, amoníaco $(\mathrm{N}, \mathrm{C})$ & 1 & Sulfato de cobre $(\mathrm{N})$, amoníaco $(\mathrm{N}, \mathrm{C})$ \\
\hline $\begin{array}{l}\text { P5 - Solventes e outras } \\
\text { substâncias auxiliares } \\
\text { mais seguras }\end{array}$ & 3 & $\begin{array}{l}\text { Etanol sem indicação de riscos para a saúde e } \\
\text { ambiente }\end{array}$ & 3 & $\begin{array}{l}\text { Etanol sem indicação de riscos para a } \\
\text { saúde e ambiente }\end{array}$ \\
\hline $\begin{array}{l}\text { P6 - Planificação para } \\
\text { conseguir eficácia ener- } \\
\text { gética }\end{array}$ & 2 & Arrefecimento a $0^{\circ} \mathrm{C}$ & 2 & Arrefecimento a $0^{\circ} \mathrm{C}$ \\
\hline $\begin{array}{l}\text { P7 - Uso de matérias } \\
\text { primas renováveis }\end{array}$ & 1 & Nenhuma das substâncias envolvidas é renovável & 1 & $\begin{array}{c}\text { Nenhuma das substâncias envolvidas é } \\
\text { renovável }\end{array}$ \\
\hline $\begin{array}{l}\text { P8 - Redução de de- } \\
\text { rivatizações }\end{array}$ & 3 & Sem derivatizações & 3 & Sem derivatizações \\
\hline P9 - Catalizadores & 3 & Sem calizadores & 3 & Sem calizadores \\
\hline $\begin{array}{l}\text { P10 - Planificação para a } \\
\text { degradação }\end{array}$ & 1 & $\begin{array}{l}\text { Pelo menos uma das substâncias envolvidas não é } \\
\text { degradável nem pode ser tratada para a sua degrada- } \\
\text { ção em produtos inócuos }\end{array}$ & 1 & $\begin{array}{l}\text { Pelo menos uma das substâncias } \\
\text { envolvidas não é degradável nem pode } \\
\text { ser tratada para a sua degradação em } \\
\text { produtos inócuos }\end{array}$ \\
\hline $\begin{array}{l}\text { P12 - Química inerente- } \\
\text { mente mais segura quanto } \\
\text { à prevenção de acidentes }\end{array}$ & 1 & Etanol (F), amoníaco(C) & 1 & Etanol (F), amoníaco(C) \\
\hline
\end{tabular}

